\title{
Informal Communication in Collaboratories
}

\section{Airong Luo}

School of Information, University of Michigan 1075 Beal Ave., Ann Arbor, MI 48105 airongl@umich.edu

This study examines how collaboratories affect informal scientific communication. Collaboratories are virtual organizations, where various information technologies are adopted to support distributed scientific work. In this paper, a framework to understand factors affecting informal communication are presented and how these factors play out in collaboratories are discussed. The results of data analysis suggest that collaboratories bring about new opportunities, but there are also barriers to informal communication in collaboratories. Peripheral scientists encounter more barriers than their partners in US and Europe. The paper concludes with a discussion of areas for future research and implications of this study.

Introduction

In recent years, collaboratories have been more and more widely adopted in distributed scientific work. William Wulf defined a collaboratory as “ ...a center without walls, in which the nation's researchers can perform their research without regard to geographical location- interacting with colleagues, accessing instrumentation, sharing data and computational resource and accessing information in digital libraries" (Wulf, 1993). The number of collaboratory projects in science and engineering has increased from three in 1993 to over 200 currently (http://www.scienceofcollaboratories.org ). A typical example of collaboratory is TB Structural Genomics Consortium (TB SGC), where 134 laboratories from 79 institutions in 15 countries participate in work to "develop a foundation for tuberculosis diagnosis and treatment by determining the 3-dimensional structures of proteins from M. tuberculosis" (http://www.doe-mbi.ucla.edu/TB ).

Collaboratories transform the geographically bounded laboratories into virtual organizations. While many hope this represents progress, we do not yet know whether they are successful. However, we do know that in order to design collaboratories which can serve the needs of distributed collaboration better, it is important to understand the 
processes of this type of remote collaboration.

It is notable that prior studies of the impact of information technology on scientific work focus on the relationship between technology use and productivity measured by publications and citations (Cohen, 1996; Hesse et al., 1993;). However, because it takes time for publications and citations to emerge and collaboratories are a relatively new phenomenon, this study focuses on one of the mediating factors that purportedly leads to productivity that appears at an early stage in the project - informal scientific communication (Fox, 1991).

Scientific communication consists of formal and informal communication. Formal communication is impersonal and occurs in scientific journals, books and at conference presentations. Informal communication is personal and often involves direct interaction. Informal collegial communication exerts a great influence on scientists' performance. It helps scientists to clarify relevance of terms, identify suitable topics, receive more timely feedback, share research methodologies (Garvey \& Griffith, 1967; Hagstrom, 1965; Pelz \& Andrews, 1976), and obtain social and emotional support (Kraut et al, 1993).

This study aims to answer the following research questions:

- In what ways do collaboratories support informal communication?

- What are the social and technical barriers to informal communication in collaboratories?

Collaboratories have been expected to advance science in two ways (Finholt, 2002): by increasing the number of participants and increasing the diversity of approaches. One way to broaden participation is to reach out to peripheral scientists such as scientists from non prestigious institutions in the US and scientists in developing countries. In particular, researchers have hypothesized that collaboratories hold great promise to benefit peripheral scientists by enabling them to communicate with researchers in prestigious universities in developed countries. To date, however, there has been no research that systematically collects the data to confirm or disconfirm this hypothesis. Thus, the study also addresses the following research question,

- Do collaboratories offer more opportunities for peripheral scientists - in the case of this study, scientists from the countries that are distant from the US and Europe where most of the active researchers reside - to participate in informal scientific communication?

The paper proceeds as follows: first, prior literature is reviewed to identify factors influencing informal communication; then how collaboratories change the way these 
factors play out are examined, hypotheses regarding the potential opportunities and barriers for informal communication afforded by collaboratories are presented; finally, results of data analyses are reported and implications of this research are discussed.

\section{A Framework to Understand Informal Communication}

Nardi and Whittaker (2002) suggest that informal communication involves two key processes: (1) establishing and maintaining communication zones; (2) information exchange. Communication zones are the social environments which precondition information exchange. The establishment and maintenance of communication zones consist of two major processes: creating social bonds that connect people to one another and managing "attention contracts" where "people agree to pay attention to one another's communication" (p85). Information exchange is the major goal of communication. In the process of information exchange, people disseminate information to and receive information from their conversation partners. When exchanging information, people try to establish and maintain social, cultural and situational common ground to ensure a productive conversation. Many social and organizational factors, such as concentration of suitable partners, mechanism for co-presence, proximity, group identity, invisible college and common ground, facilitate the process of establishment and maintenance of communication zones and information change (see Figure 1).

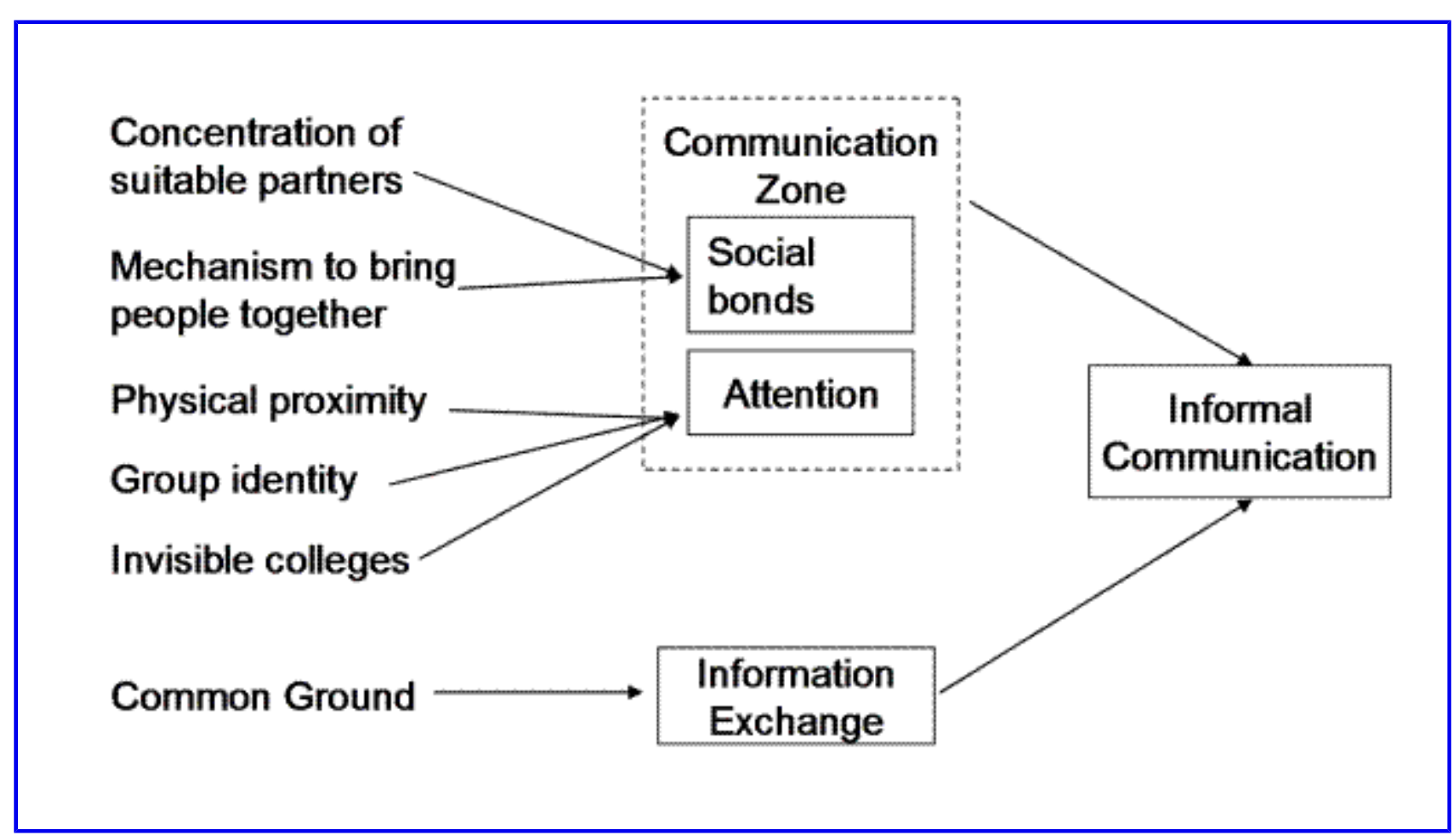

Figure 1. A Framework to Understand Informal Communication 
Systems supporting informal communication should help increase opportunities for people to meet and connect with their suitable partners - people who share common research interests or people who work on similar projects. One way to increase such opportunities is to concentrate suitable partners (Kraut et al., 1993). A research organization accomplishes the concentration of suitable partners by placing the people working on the same project or sharing the same research interests close to each other.

When a pool of potential suitable communication partners is available, it is important that there exists an "environmental mechanism" which allows co-presence of people - bringing people together. In organizations, this mechanism can be a hallway, a cafeteria, coffee lounge or other places where people can meet and start spontaneous conversations (Kraut et al., 1993). However, opportunities for researchers to reach suitable partners do not guarantee that others will pay attention to their communication. There should be mechanisms enabling researchers to obtain other people's attention. Research institutions and scientific community help researchers in their management of "attention contracts" in the following ways:

First, proximity facilitates informal communication (Kiesler \& Cummings, 2002; Kraut et al., 1988). In organizations, communication is usually face-to-face. The mere physical presence of another person creates an obligation for conversation partners to be engaged. In addition, in an organizational setting, frequent encounter improves people's feelings of familiarity with one another, and consequently increase the frequency of contact among colleagues (Kiesler \& Cummings, 2002).

Second, group identity motivates people to communicate with their group members. Constant et al. (1996) find that in a global computer manufacturer, information seekers receive help from information providers even though they lack personal connections with each other. They suggest that people help each other on the computer network, because they belong to the same organization and they are concerned with offering help to solve organizational problems.

Third, researchers communicate with colleagues outside their affiliated institutions through invisible colleges. An invisible college consists of around 100 elite researchers who regularly exchange information or preprints of papers about the newest research progress (Price, 1971). These colleges usually arise around nuclei of major researchers in different fields. Thus, there exists a status hierarchy in an invisible college, which directly affects scientists' opportunities to access communication channels. Those at the center of invisible colleges can gain most attention from the other people and have most opportunities for informal communication. Peripheral researchers, who cannot have 
access to and obtain attention from any member of the invisible colleges, have few opportunities for informal communication.

\section{Information exchange}

Informal communication occurs in different contexts and takes place between people from different social and cultural backgrounds. Thus, in order to ensure the quality of communication, conversation partners need to establish and maintain common ground in the process of information exchange (Olson \& Olson, 2000). Common ground refers to "knowledge that the participants have in common, and they are aware that they have it in common" (p. 157). Common ground is established both through cultural and social knowledge embedded in a social and organizational setting, and also through situational knowledge such as individuals' gestures, and behavior in conversations.

When working in the same organization, people usually share the same social and organizational culture, which helps them to gain the knowledge of who is expert in which field, and from whom they can seek help. Thus, it is easier for researchers working in the same institution to identify appropriate partners with whom they can discuss their research questions.

Sharing more immediate situational knowledge provides participants in interpersonal interactions with an understanding of their partners' mental and behavioral states. For example, when people are aware of the mental state of the conversation partners, they know when to start a difficult topic. In addition, in order to understand their partners, people need to know the object their partners are talking about during a conversation. The informal communication within an organization is often face-to-face communication, where various visual cues help people to establish and maintain common ground. For instance, people can look at the conversation initiator as a cue for starting an utterance. In face-to-face contexts, it is also easier for people to share objects during the conversation.

\section{Potential Opportunities for Informal Communication in Collaboratories}

Collaboratories, which enable scientists to overcome geographical barriers and reach their remotely located colleagues, may offer scientists new opportunities for informal communication. In the following part, the potential opportunities and barriers for informal communication in collaboratories are discussed based on the framework of informal communication outlined above.

The increased ease of communicating via information technology increases the feasibility 
and size of distance collaboration (Finholt \& Sproull, 1990; Moon \& Sproull, 2002). A broader collaboration means that collaboratories can concentrate scientists who share similar research interests or work on similar projects even though they are not collocated. At the most basic level, collaboratories may help scientists stay informed about who is doing similar research and with whom they can communicate and collaborate. They may create opportunities for scientists to connect with other researchers from other institutions and other countries. In addition, in collaboratories, information technology, such as instant messaging, email listservs, web forums are used to bring scientists all over the world together. Instant messenger can help to build a space for scientists' opportunistic encounter; email listservs and web forums create a space for "asynchronous meeting"researchers do not come to the space at the same time, but they can still disseminate to and obtain information from others.

Moreover, collaboratory members usually share the same research goal. Belonging to a collaboratory can help distributed researchers obtain a sense of group identity. Thus, collaboratory members might be willing to communicate with other researchers and answer the questions of those who belong to the same collaboratory

Peripheral scientists, for example, scientists who are distant from US and Europe where most major scientists reside, are isolated (Gaillard, 1993) and have few chances to access invisible colleges. Collaboratories hold the promise to extend the contact network of peripheral scientists by enabling them to collaborate and communicate with their remotely located colleagues in the developed world. Thus, collaboratories have the potential to transform invisible colleges and reduce the inequality in opportunities for scientists to access informal communication channels.

\section{Potential Barriers to Informal Communication in Collaboratories}

Despite new opportunities, distance and social factors may impose barriers to informal communication in collaboratories.

Though information technology increases the possibility for scientists to reach a larger group of researchers, it cannot guarantee actual communication.

First, distance communication is often realized through information technology, which enables one-to-many and many-to-many forms of communication, such as electronic bulletin boards and email group lists. When these technologies are used, the availability of communication partners may be too diffused - everybody in the collaboratory can receive the message. When a global message is sent out, it is difficult for the receivers to know to whom the message is specifically addressed. Thus, people might be less motivated to 
answer a question.

Second, "the lack of real and perceived presence of others and lack of shared social settings" hinders communication (Kiesler \& Cummings, 2002). In face-to-face contexts, the presence of others increases attention, social impact, and familiarity. Thus, people feel a stronger urge to communicate. By contrast, in distributed work, where people are out of one another's sight, they do not pay as much attention, and thus are not in as frequent contact with their coworkers (Kiesler \& Cummings, 2002). Empirical studies also show that people communicate most often with those who are physically close (Allen, 1977, Kraut et al, 1988). In Allen's data, about $25 \%$ of engineers whose offices were next door to each other (less than 5 meters apart) discussed technical topics at least once a week; if their offices were 10 meters apart, this figure dropped below $10 \%$.

It is also difficult for researchers to establish and maintain common ground In collaboratories. In collaboratories, researchers work with others who are from different countries and different organizations, and with whom they have had little prior contact. It can be difficult for them to understand each other's social and organizational background. In face-to-face contexts, the presence of various rich contextual cues makes it easy to establish common ground. Thus, researchers believe that successful computer mediated communication can be achieved through creating the feeling of co-presence (Lombard \& Ditton, 1997). When designing technologies to support distance communication, researchers operationalize co-presence in terms of communication cues that enable the establishment of common ground in face-to-face interactions (Whittaker \& O'Connail, 1997). The design of technology focuses on how to transmit these cues in a timely way (Churchill \& Bly, 1999). However, numerous attempts to create the sense of co-presence remotely have been all abandoned, partly because their costs outweighed their benefits (Olson \& Olson, 2000). Thus, it is not unreasonable to conclude that communicating through information technologies is still not as successful as collocation in creating environments which can support the establishment and maintenance of common ground as collocated situations.

Real-time conversation between distance collaborators requires scientists to have access to advanced computer systems and network infrastructure. However, as we all know, there exists a digital divide in Internet use caused by inequality in access to the Internet (DiMaggio et al., 2001). An example of the digital divide in the scientific community can be seen from a 2003 report on geographic issues of network access (Williams et al., 2003). This report compared figures for three groups of countries in Europe: (1) the European Economic Area, (2) the ten countries that join the European Union in May 2004, (3) and a number of other countries neighboring the European Union. On average the typical core capacity of the national research network is five times smaller in the second 
group of countries than in the first group, and 25 times smaller in the third group of countries. The consequences of this digital divide might be serious, especially in an age when the international research community is moving rapidly to adopt various forms of collaborative e-science. This implies that in the future only those researchers who have access to a high-capacity network can access the channels of informal communication. Scientists from countries which are unable to afford advanced network will be excluded.

\section{Method}

This study takes a qualitative approach to identify how informal communication occurs in collaboratories and how it affects collaboratory participants. Eight collaboratories which include participants from both US and Europe and countries distant from the US and Europe in a database of more than $\mathbf{2 0 0}$ collaboratory projects were identified (http://www.scienceofcollaboratories.org ). The field, size and number of participants interviewed for each collaboratory is shown in Table 1. Participants from countries distant from the US and Europe are included in order to test whether collaboratories equalized scientists' participation in informal communication. Among the collaboratories studied, only one provides funding to its participants. The other collaboratories do not provide funding, but offer resources, such as expensive scientific instruments. In US and Europe, six US scientists and one from Germany were interviewed. For scientists from other countries, seven from China, five from Korea, one from New Zealand, one from India, one from Taiwan and one from South Africa were interviewed.

Identifying that the designation of science originating in a country distant from the US and Europe may not be equivalent to non-world-class science (e.g., China does world-class seismology research) (Wagner et al., 2001). Consequently the relative publication impacts of these countries in the past $\mathbf{1 0}$ years in the fields studied were examined. They are all below the world average (http://www.in-cites.com ).

An interview protocol with open-ended questions was developed. Participants were asked about how they became involved in the collaboratory, the benefits they obtained from it and the barriers to its use. They were also asked to describe their collaborative work, their communication with other collaboratory members, and technologies used in the process of communication.

Adopting the interpretive approach, interviews were transcribed first and then text was interpreted during the analysis (Miles \& Huberman, 1994). An inductive approach was used for interpretation and categories (e.g. communication infrastructure, access to colleagues, technology used etc.) were developed from the data. Then based on the 
categories, concepts (benefits, barriers etc.) from the data were sorted. An examination of the sorted data identified patterns and relationships. Data analysis concentrated on the individual level of analysis and involved code allocation to text sections.

The web content, such as web forums and meeting minutes provided by the websites of the collaboratory projects were also exmined. In addition, the documents, if there were any, such as annual reports offered by the projects were examined.

Table 1. Collaboratories Studied

\begin{tabular}{|c|c|c|c|}
\hline Collaboratory & Field & Distribution of collaborators & $\begin{array}{c}\text { Number of participants } \\
\text { interviewed }\end{array}$ \\
\hline A & $\begin{array}{l}\text { Biomedical } \\
\text { science }\end{array}$ & $\begin{array}{c}1 \text { lab in the US and three labs in } \\
\text { China }\end{array}$ & 1 US and 2 China \\
\hline B & Molecular biology & 30 labs in 6 countries & 2 China \\
\hline C & Molecular biology & 55 labs from 12 countries & 2 Korea, 1 US, 1 China \\
\hline D & Molecular biology & About 246 participants & $\begin{array}{c}1 \text { US, } 1 \text { Korea, } 1 \text { South Africa , } 1 \\
\text { Taiwan }\end{array}$ \\
\hline $\mathbf{E}$ & Molecular biology & 134 labs in 15 countries & $\begin{array}{c}1 \text { US, } 1 \text { Korea, } 1 \text { New Zealand, } 1 \\
\text { India }\end{array}$ \\
\hline $\mathbf{F}$ & $\begin{array}{l}\text { High energy } \\
\text { physics }\end{array}$ & 86 institutes in 29 countries & 3 US, 1 China \\
\hline G & $\begin{array}{l}\text { High energy } \\
\text { physics }\end{array}$ & 160 institutions in 36 nations & 1 Germany, 1 Korea \\
\hline $\mathbf{H}$ & $\begin{array}{l}\text { High energy } \\
\text { physics }\end{array}$ & 47 institutions in 15 countries & 1 Chinese \\
\hline
\end{tabular}

\section{Findings}

As suggested by the literature review, participants reported both opportunities for and barriers to informal communication in collaboratories.

\section{Opportunities for Informal Communication}

Collaboratories offer scientists increased opportunities to communicate with their remotely located colleagues. A scientist in New Zealand reported that the collaboratory gives him and his colleagues "much greater connection with the rest of the world, for new technologies, for new ideas." 
The participants also reported that collaboratories support informal communication in the following ways:

First, collaboratories help to concentrate suitable partners. Seven among the eight collaboratories studied adopted an open policy, such that any scientist who is interested and whose research goal matches the broadly defined goal of the collaboratory can participate. The only condition is that scientists need to follow the policy of the collaboratory, which usually asks them to release their data publicly and credit the collaboratory in their publications when using data derived from the collaboratory. In this way, collaboratories concentrate people who share similar research interests from all over the world, and thus scientists can be informed about who is doing similar work and who they can contact for further information.

Second, collaboratories also provide various forums for scientists to interact with each other. All the collaboratories studied hold annual meetings, where participants can get to know each other and present their research. Participants especially value the personal contact they can have with other scientists in these meetings.

Third, two among the eight collaboratories studied provide databases where scientists can share their recent work and unpublished data such that they can obtain more timely information about others' research. These databases also offer an example of informal communication channels which can only be facilitated by information technology. In two molecular biology collaboratories studied, participants are required to post their working progress and their research methods. These databases help scientists to avoid repetitive work and provide an opportunity for scientists to learn research methods from each other. Figure 2 and Figure 3 demonstrate a section of such a database in a molecular biology collaboratory. From Figure 2, we can see that the database includes information about the investigator, what the experiment is about and the results of data analyses. Figure 3 contains more detailed information about a particular investigator's experiment. It explains when and how the experiment is done, what kinds of materials are used, etc.

In seven among the eight collaboratories studied, the presentations and meeting notes of all the research meetings are posted online, so that people who cannot attend also have access to that information. Posting presentations and meeting notes online offers another informal communication channel, which can only be afforded by information technology.

Some collaboratories also enhance members' group identity by requiring researchers to contribute their data in exchange for data analysis services. For example, in two of the collaboratories, scientists can send their samples to the US to have their data analyzed by on-site instruments there. In exchange, as shown in Figure 2 and Figure 3, these data 
should be made public after the scientists hold them for a certain time, six weeks in the case the two collaboratories studied.

Collaboratories help transform invisible colleges. Peripheral scientists reported that collaboratories help connect them to those from the US and Europe. In particular, sharing recent work and research methodology enables them to be informed about the latest developments and learn from the scientists in the US and Europe. A Korean scientist reported,

"I like this database. From the publications, you can only get the success stories. But in this database, people also reported their failure experiences, and I learned a lot from people's failure. If I know that method did not work, I will not use that method in my research."

Being distant and lacking of travel funding, it is difficult for peripheral scientists to attend many research meetings and conferences. Records provided by collaboratories give them a chance to know what was presented and discussed. A high energy physicist in China reported that he could seldom go to conferences due to budget and visa problems, but he "read" most of the presentations.

\begin{tabular}{|c|c|c|c|c|c|c|}
\hline Investigator & MicroArray Experiment & $\begin{array}{l}\text { Samples } \\
\text { Analyzed }\end{array}$ & Data Files & $\begin{array}{l}\text { Gene-chip } \\
\text { version }\end{array}$ & \multicolumn{2}{|c|}{ Data Analysis } \\
\hline filter & fiter & & & & Low level & $\begin{array}{l}\text { High Level } \\
\text { (if pertormed } \\
\text { by Core E) }\end{array}$ \\
\hline steven Rosen & $\begin{array}{l}\text { Gene expression in } \\
\text { experimentally injured and } \\
\text { controt mouse spinal cords }\end{array}$ & $\begin{array}{l}\text { MicroArray } \\
\text { Samples }\end{array}$ & $\begin{array}{l}\text { Dec } 25,05 \\
\text { Des }\end{array}$ & GLYCO_v2 & 5 d & \\
\hline Martin Lot $z$ & $\begin{array}{l}\text { ML 6: Impact of mediator } \\
\text { nitric oxide on gene } \\
\text { expression in human } \\
\text { chondrocytes. Expanded } \\
\text { Study }\end{array}$ & $\begin{array}{l}\text { MicroArray } \\
\text { Samples }\end{array}$ & $\begin{array}{l}\text { a } \\
\text { Dec 06, 05 }\end{array}$ & Gerco_v2 & 8 & i \\
\hline Susan Fisher & $\begin{array}{l}\text { Susan Fisher 1: Effects of } \\
\text { estrogen and progesterone } \\
\text { on glycosyltransferase } \\
\text { expression in mice }\end{array}$ & $\begin{array}{l}\text { Microarray } \\
\text { Samples }\end{array}$ & $\begin{array}{l}\text { B] } 3 \text {. } \\
\text { Nov 19,05 }\end{array}$ & GLYCo_v2 & (5) & $3^{x}$ \\
\hline Minoru Fukuda & $\begin{array}{l}\text { Changes in gene expression } \\
\text { during the transition from } \\
\text { inflammation to cancer } \\
\text { following Helicobacter felis } \\
\text { infection }\end{array}$ & $\begin{array}{l}\text { MicroArray } \\
\text { Samples }\end{array}$ & $\begin{array}{l}\text { 8. } \\
\text { oct } 10,05\end{array}$ & GLYCO_v2 & 3 & \\
\hline Celso A. Reis & $\begin{array}{l}\text { Celso Reis 1: Gene } \\
\text { expression changes in the } \\
\text { gostric epithelial cells } \\
\text { introduced by Helicobacter } \\
\text { pylori infection }\end{array}$ & $\begin{array}{l}\text { MicroArray } \\
\text { Samples }\end{array}$ & $\frac{9}{\operatorname{sep} 26,05}$ & atrco_v2 & 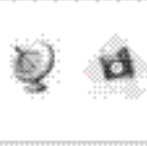 & a \\
\hline
\end{tabular}

Figure 2. A section of MicroArray data in a molecular biology collaboratory 


\section{Micro Array Experiment : MAEXP_281_100505}

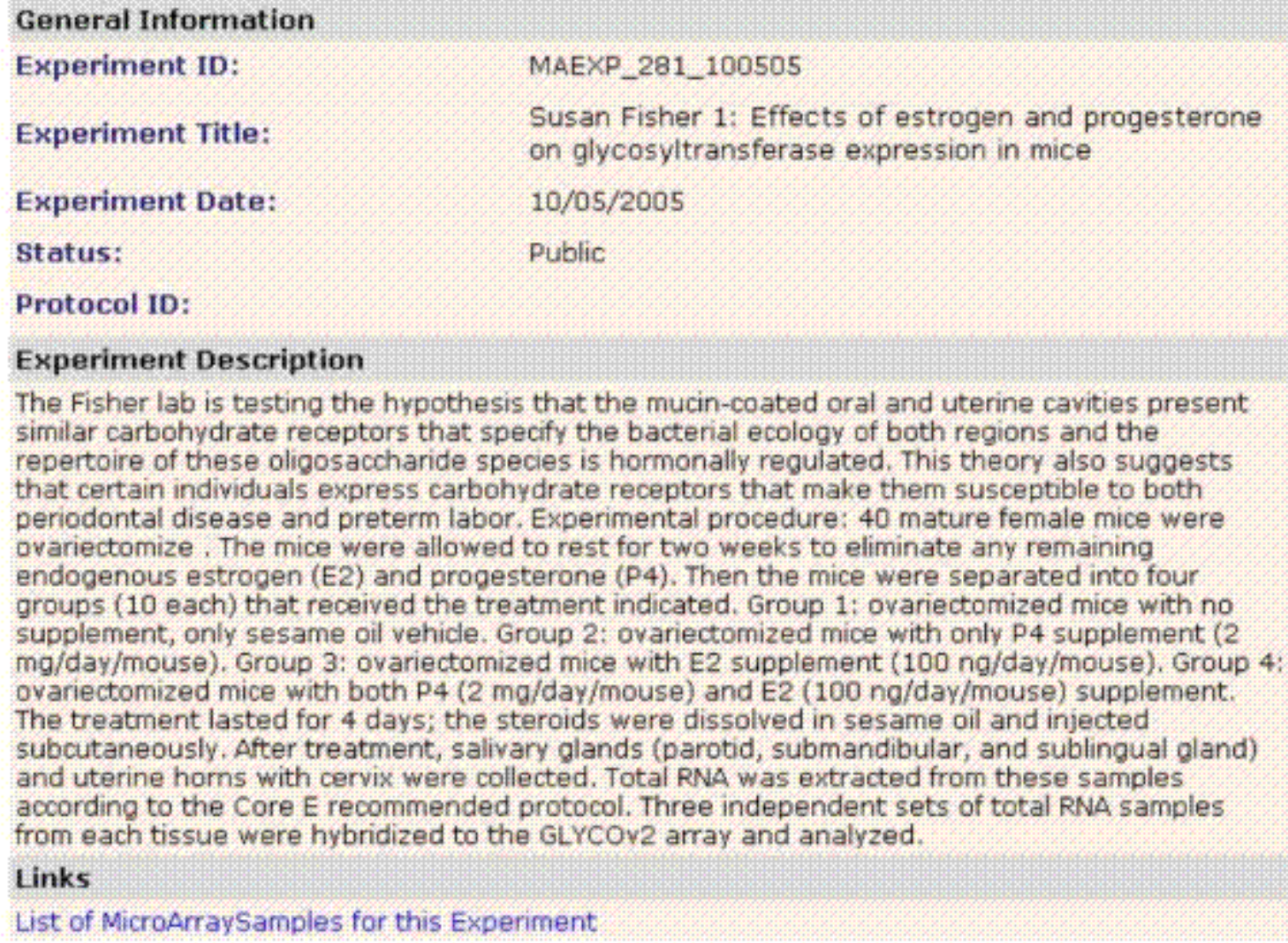

Figure 3. Micro Array Experiment : MAEXP_281_100505

(Sources: <http://www.functionalglycomics.org/static/consortium/ >)

Though collaboratories allow scientists to reach remotely located experts, they still have some limitations. Peripheral scientists tend to report more barriers.

\section{Barriers to Informal Communication}

Collaboratories offer scientists opportunities to establish social bonds with other researchers. For many scientists the social bonds only mean they know who is working in the same area and what they are working on. They never really meet and conduct simultaneous communication with each other. Theoretically, by concentrating scientists who share similar research interests, and the mechanisms of information technology such as email, instant messenger, and web forums, allow scientists to seek help from other collaboratory members informally (Constant et al., 1996). However, scientists do not take advantage of these resources as often as expected. Scientists still prefer to discuss research questions with their local colleagues. Teleconferencing and scheduled videoconferencing tend to be used for more formal and scheduled communication, such 
as discussing research plans or decision making. None of the scientists interviewed use instant messenger to contact other collaboratory members in other organizations, and discussion forums are seldom used though often provided. When asked about the infrequent use of information technology to discuss research questions, all the scientists answered they did not think instant messenger is suitable for scientific discussion among collaboratory members. In addition, all the scientists interviewed thought that it was more efficient to ask questions through email than web forums. In collaboratories where scientists are required to communicate their activity and research methods through the databases, three scientists interviewed in this study reported that scientists in the collaboratories often forget to share information as expected.

Though many collaboratories adopt an open policy, and theoretically all peripheral scientists have opportunities to participate, all the peripheral participants interviewed in the study have worked or studied in the US or Europe and had been introduced to the collaboratories by their former advisers or mentors. This means that to a certain extent collaboratories help to extend invisible colleges, but still mainly accessible to those who have prior access to invisible colleges.

Scientists value the opportunities for personal contact. Participants reported that annual meetings and working side by side are still the most efficient and effective way for people to become socially bonded and receive latest information about the development in the field.

A scientist studying molecular biology in New Zealand commented that he really appreciated the annual retreat organized by the collaboratory. When asked about why the retreat is helpful, he said,

"Just talking to other investigators. That often helps to clear any problems, any questions. It's just the personal contact is very valuable. Although I already knew some people before the [the collaboratory] was formed, there were many more who became part of it since then. And I got to know them."

When asked about the importance of conferences, a high energy physicist in the US said,

"There are two types of conferences for me: The first type is the conference from which I only want to know what is presented. I will not go to these conferences, because I can download slides from the web. The second type is the conference where I want to meet people and talk to them face-to-face about their research and my own research. I will definitely go to the second types of conferences."

However, people in the collaboratories do not have the same opportunities to attend 
conferences. For example, the limited travel funding placed peripheral scientists in disadvantaged situations. Both Korean and Chinese scientists reported that their local funding agencies usually provide very limited amount of travel funding. Unable to attend conferences as often as their partners in the developed world, peripheral scientists tend to be out of sight of other collaboratory members. According to Nardi and Whittaker (2002), communication zones tend to degrade over time, and face-to-face interactions can help people to refresh their communication zones. Being out of the sight of other collaboratory members makes the communication zones for peripheral scientists degrade faster. They are easier to be neglected. In a molecular biology collaboratory, a participant from Korea and a participant from Taiwan reported that they seldom contacted other collaboratory members. They only benefited from the data analysis service provided by the collaboratory. By contrast, a US scientist, who participates in the same collaboratory, reported that he contacted other members whom he knew from the annual meeting of the collaboratories. He asked them for information about their recent research development, and exchanged reagents and some materials needed for experiments with them. However, he said,

"I only know some active members of the collaboratory. ...By active, I mean those who show up in the conferences organized by the collaboratories and those who contribute data to the collaboratory."

In six collaboratories among the eight collaboratories studied, most of the members are from the US and Europe. It is convenient for them to visit each other often and work together. They can renew their communication zones often. A few peripheral scientists who they cannot see often tend to be out of their attention sometimes. A high energy physicist in China expressed his concern about the situation.

"Not being able to travel frequently makes us isolated. We are now building detector, so the problem is not so serious. But after the experiments start and we have data, and when we need to do physics [meaning the task will be more ambiguous], we need to be there, to sit with other scientists and express out opinions. I don't know what we can do at that time."

In collaboratories, some communication problems are also caused by the uneven infrastructure of information technology. When scientists talk about research problems, they often need to view data at the same time to establish common ground. They need information technologies to accommodate this need, such as video conferencing systems. However, scientists in China reported that they cannot afford video conferencing. Not being able to view the data during the discussions, scientists could not gain common ground as described by an AIDS researcher in China, 
"Currently when we have teleconference, we can only discuss the data. But we can't view the data and discuss the data at the same time. When we discuss data, we only do oral interpretation. I think this is the largest deficiency. In the process of research, if you can't view the data, and only listen to people describing them and express your opinion, it will be too limited. It will depend on whether the describer can describe correctly and whether people who try to understand can understand correctly."

\section{Conclusion}

This study demonstrates that collaboratories offer scientists new opportunities for informal communication, a key ingredient in increasing productivity. It also identifies barriers to informal communication in collaboratories. Identifying those barriers can help us to understand how to overcome them.

First, some information technologies such as instant messenger and web forums, which can be used to bring people together are not adopted by scientists to communicate with other collaboratory members. Further studies are needed to examine the reason and how to further encourage collaboratory members to use these technologies.

Second, some information technologies such as databases and web forums, are efficient tools for scientists to record their working progress, research methodology and failure experiences. They enable scientists to communicate with and learn from each other. However, unaware of these benefits to others, scientists often forget to record their work. Thus, participants of collaboratories should be reminded from time to time that their partners are remotely located, and they should record their activity and research methods, and share them with their partners.

Third, limited travel funding hinders some scientists from benefiting from collaboratory use. Peripheral scientists value the opportunities to meet other collaboratory members face-to-face. They also appreciate chances to work collocatedly with their partners from the US and Europe. However, because of the limited travel funding, they cannot go to conferences or travel to their partners' labs as often as they can. Because they cannot meet their partners face-to-face very often, they tend to be neglected by their partners in developed countries. Thus, in order to improve communication and interactions between collaboratory members, collaboratories should provide some travel funding to those who do not have sufficient travel funding.

Finally, since some scientists cannot afford high end technologies, collaboratories should look for solutions that do not require highly advanced communication infrastructure. For 
example, instead of video conferencing technologies, they can apply low bandwidth technologies that also allows data sharing with voice over IP

Collaboratories are more and more widely adopted and become increasingly important for scientific work. It is imperative for researchers to understand their effects on all participants.

\section{References}

Allen, T. J. (1977) Managing the flow of technology Cambridge, Masachusetts: The MIT Press

Churchill, E., \& Bly, S. (1999) Supporting work activity with lightweight tools ACM GROUP, Phoenix, Arizona

Cohen, J. A. (1996) Computer mediated communication and publication productivity among faculty Internet research 6(2/3), 41-63

Constant, D., Sproull, L., \& Kiesler, S. (1996) The kindness of strangers: The usefulness of electronic weak ties for technical advice Organization Science 7(2), 119-135

DiMaggio, P., E., Hargittai, W. N., \& J.P., R. (2001) Social implications of the internet Annual Review of Sociology 27, 307-336

Finholt, T. A. (2002) Collaboratories Annual Review of Information Science and Technology 36, 77-107

Finholt, T. A., \& Sproull, L. (1990) Electronic groups at work Organization Science 1, 41-64

Fox, M. F. (1991) Research productivity and the environmental context In T. G. Whiston \& R. L. Geiger (Eds.) Research and higher education Buckingham, :Open University press

Gaillard, J. (1993) Scientists in the third world Kentucky: The University Press of Kentucky

Garvey, W. D., \& Griffith, B. C. (1967) Scientific communication as a social system Science 157(3792), 1011-1016

Hagstrom, W. O. (1965) The scientific community New York: Basic books Hesse, B. W., Sproull, L. S., Keisler, S. B., \& Walsh, J. P. (1993) Returns to science: Computer networks in oceanography Communications of the ACM 36(8), 90-101

Kiesler, S., \& Cummings, J. (2002) Proximity and distance in work groups In P. J. Hinds \& S. Kiesler (Eds.) Distributed work Cambridge, Massachusetts: MIT Press. 57-80 
Kraut, R., Egido, C., \& Galegher, J. (1988) Patterns of contact and communication in scientific research collaboration Computer Supported Cooperative Work 1988

proceedings 1-12

Kraut, R., Fish, R. S., Root, R., \& Chalfonte, B. (1993) Informal communication in organizations: Form, function and technology In R. Backer (Ed.) Readings in groupware and computer supported cooperative work Morgen Kauffman

Lombard, M., \& Ditton, T. (1997) At the heart of it all: The concept of presence Journal computer mediated communication 3(2)

Miles, M. B., \& Huberman, M. A. (1994) Qualitative analysis: An expanded sourcebook Thousand Oaks, CA: Sage

Moon, J. Y., \& Sproull, L. (2002) Essence of distributed work: The case of the linux kernel In P. J. Hinds \& S. Kiesler (Eds.) Distributed work Cambridge, Massachusetts: The MIT Press. pp. 381-404

Nardi, B., \& Whittaker, S. (2002) The place of face-to-face communication in distributed work In P. J. Hinds \& S. Kiesler (Eds.) Distributed work Cambridge, Massachusetts: MIT press. pp. 83-110

Olson, G. M., \& Olson, J. S. (2000) Distance matters Human-Computer Interaction 15, 139-178

Pelz, D. C., \& Andrews, F. M. (1976) Scientists in organizations: Productive climates for research and development Ann Arbor, Michigan: Institute for social research

Price, D. J. d. S. (1971) Some remarks on elitism in information and the invisible college phenomenon in science Journal of the american society for information science (22), 74-75

Wagner, C. S., Brahmakulam, I., Jackson, B., Wong, A., \& Yoda, T. (2001) Science and technology collaboration: Building capacity in developing countries Rand Science and technology

Whittaker, S., \& O'Connail, B. (1997) The role of vision in face-to-face and mediated communication In K. E. Finn \& S. B. Wilbur (Eds.) Video-mediated communication Lawrence Erlbaum Associates. pp. 23-49

Williams, D., Bona, M., Butterworth, I., Davies, D., Jaume-Rajaonia, S., Mayer, T., et al. (2003) Study into European research and education networking as targeted by europe: SERENATE

Wulf, W. A. (1993) The collaboratory opportunity Science 261(5123), 854-855 